\title{
Effect of spray drying on volatile compounds of acerola pulp
}

\author{
Nogueira, P. M. ${ }^{a}$; Leite Neta M. T. ${ }^{\text {a }}$ Araujo, H. C. S. ${ }^{a}$; Jesus, M. S..$^{\text {; }}$ Shanmugam, S..$^{\text {; }}$ \\ Narain, N. ${ }^{a}$
}

${ }^{a}$ Laboratory of Flavor and Chromatographic Analysis, Federal University of Sergipe, Av. Marechal Rondon, s/n, Jardim Rosa Elze, 49100-000, São Cristóvão, SE, Brazil

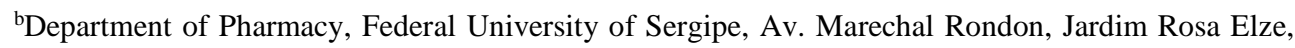
CEP: 4910 0-000 São Cristóvão, Sergipe, Brazil

*E-mail of the corresponding author: narendra.narain@gmail.com

\begin{abstract}
The objective of this work was to optimize the drying conditions in order to obtain acerola powder and to focus on the product aroma quality. Acerola fruits were selected, washed and sanitized before extracting the pulp. An emulsion was obtained by adding maltodextrin in the pulp. The dehydrated powders were obtained in spray dryer by drying at inlet temperatures of 128 and $152{ }^{\circ} \mathrm{C}$. Twenty five volatile compounds were identified in fresh acerola pulp and in the dehydrated powder. These results prove that use of maltodextrin in spray drying of acerola pulp helps in retention of key aroma compounds in acerola powder.
\end{abstract}

Keywords: Acerola, Spray drying, dehydration, volatiles, aroma, GC-MS.

$21^{\text {ST }}$ INTERNATIONAL DRYING SYMPOSIUM EDITORIAL UNIVERSITAT POLITÈCNICA DE VALÈNCIA 


\section{Introduction}

The aceroleira is a fruit tree native to the Antilles, North of South and Central America, that showed good adaptation in several countries being mainly cultivated in Brazil. ${ }^{[1]}$ Its potential as a natural source and capacity for industrial use has attracted the interest of fruit growers and it has attained economic importance in several regions of Brazil. ${ }^{[2]}$ The acerola (Malpighia glabra) is a fruit species widely accepted by consumers, which has been prominent in Brazil and the world, mainly because it is one of the main natural sources of vitamin $\mathrm{C}$ and carotenoids and it is widely industrialized in the form of frozen pulp, characterizing as functional foods, since it confers benefits in reducing the risk of some non-transmissible chronic diseases such as cancer. ${ }^{[1]}$

The transformation of acerola fruit into an industrial product will allow its preservation for a prolonged period, but it is also required that the beneficial properties and the fruit's sensorial characteristics will be maintained to its maximum. ${ }^{[3]}$ Among the techniques used to maintain post-harvest quality of fruit, dehydration, besides being used as a conservation method, prevents deterioration and losses of commercial value and adds value to the product giving rise to a new option in the market. ${ }^{[4]}$

The spray drying consists of the transformation of the product from the fluid state to dry particles in the form of powder. The dried powder should retain maximum initial characteristics of the fruit pulp and protect it from the adverse conditions of the external environment. For this purpose wall materials or microencapsulants are incorporated into the pulp before drying. ${ }^{[5]}$ Thus, the present work had as objective to optimize the drying conditions of the parameters for atomization of the acerola pulp in spray dryer and evaluate its effect on the volatile compounds of acerola pulp.

\section{Materials and Methods}

\subsection{Fruits purchase}

The ripe fruits of acerola were acquired from the Central Market of Supply (CEASA) in the city of Aracaju/SE. The fruits were then taken to the Laboratory of Processing of Vegetable Origin (LPOV), located in the Department of Food Technology (DFT) at the Federal University of Sergipe (UFS).

\subsection{Sanitation and pulp extraction}

The selected fruits were submitted to selection, sanitization in a solution of $200 \mathrm{ppm}$ of residual chlorine (Sumaveg®) for 10 minutes to eliminate possible microorganisms that 
withstood the previous step. The rinse was carried out in solution at $3 \mathrm{ppm}$ of active chlorine for 10 minutes. After the rinsing the fruits were washed in water for 10 minutes to remove all chlorine and pulped in a stainless-steel pulp (ITAMETAL), using a $1.5 \mathrm{~mm}$ diameter screen. The pulp was weighed and packed in polyethylene packages. The packages with the pulps were stored in a freezer at freezing temperature $\left(-21^{\circ} \mathrm{C}\right)$.

\subsection{Spray Drying Process}

For the Spray dryer atomization process, tests were carried out by varying the drying air temperature and the carrier agent concentrations, as detailed in Table 1.

Table 1. Formulations and Temperatures used in spray drying process in obtaining dried powder from acerola pulp.

\begin{tabular}{ccccc}
\hline $\begin{array}{c}\text { Sample } \\
\text { code }\end{array}$ & $\begin{array}{c}\text { Pulp } \\
(\boldsymbol{\%})\end{array}$ & $\begin{array}{c}\text { Maltodextrin } \\
(\boldsymbol{\%})\end{array}$ & $\begin{array}{c}\text { Input Temperature } \\
\left({ }^{\mathbf{0}} \mathbf{C}\right)\end{array}$ & $\begin{array}{c}\text { Output Temperature } \\
\left({ }^{\mathbf{0}} \mathbf{C}\right)\end{array}$ \\
\hline AC 1 & 86 & 14 & 128 & 65 \\
AC 2 & 86 & 14 & 152 & 78 \\
AC 3 & 74 & 26 & 128 & 65 \\
AC 4 & 74 & 26 & 152 & 78 \\
\hline
\end{tabular}

The spray drying was performed in a spray dryer (LABMAQ, model MSDi 1.0, Riberão Preto-SP, Brazil) with injector nozzle having the orifice of $1.2 \mathrm{~mm}$ diameter, air flow of $4.00 \mathrm{~m}^{3} / \mathrm{min}$ and air pressure of $4 \mathrm{kgf} / \mathrm{cm}^{2}$. The dryer was fed through a peristaltic pump, with rotation speed adjusted as a function of the maximum speed; the flow was $0,44 \mathrm{~L} / \mathrm{h}$. Samples were produced with 14 and $26 \%$ of maltodextrin and the two inlet temperatures used were 128 and $152{ }^{\circ} \mathrm{C}$ (Table 1).

\subsection{Determination of Volatile Compounds}

The volatile composition of the acerola fresh pulp and dried powder was determined using the purge and trap (P\&T) technique by varying 3 different dilutions of the pulp with water (4g:10mL, 4g:20mL and 4g:30mL). The volatiles were captured and concentrated in the P\&T system (Tekmar, Model ATOMX, Mason-45040, USA) under the following conditions: $4 \mathrm{~g}$ of pulp were diluted with $10 \mathrm{~mL}$ of distilled water and taken to the purge and trap system, operating with helium gas flow of $40 \mathrm{~mL} / \mathrm{min}$, purging time of $11 \mathrm{~min}$, desorption time of $5 \mathrm{~min}$ in a trap containing Tenax/silica gel/charcoal.

$21^{\text {ST }}$ INTERNATIONAL DRYING SYMPOSIUM EDITORIAL UNIVERSITAT POLITÈCNICA DE VALÈNCIA 


\subsection{Separation and Identification of Volatile Compounds}

The P\&T system used the Vocarb3000 trap and analyzed in the gas chromatography system coupled to a mass spectrometer (GC-MS QQQ Agilent 7000). The compounds were separated on carbowax capillary column (30 m x $0.25 \mathrm{~mm} \times 0.25 \mu \mathrm{m})$ using helium as the carrier gas $(1.0 \mathrm{~mL} / \mathrm{min})$. The temperature of the injector was $220^{\circ} \mathrm{C}$ and the column temperature programming was: $35^{\circ} \mathrm{C}$ for $2 \mathrm{~min}$, increase at $10^{\circ} \mathrm{C} / \mathrm{min}$ to $100^{\circ} \mathrm{C}$, maintaining for $1 \mathrm{~min}$ followed by an increase of $3^{\circ} \mathrm{C} / \mathrm{min}$ to $250{ }^{\circ} \mathrm{C}$, totaling $59 \mathrm{~min}$ of analysis.

The identification of the volatile compounds was performed by comparing the mass spectra of the sample compounds with those in the NIST (National Institute of Standards \& Technology), containing approximately 150,000 reference spectra and by comparing the linear retention index (LRI) of the compounds with those of publications in the literature and LRI calculated on the basis of the retention times of a series of n-alkanes mixtures of C8-C30, C8-C40 and C8-C17, injected at identical analytical conditions.

The linear retention index (LRI) was calculated based on the retention time of the authentic alkane standards versus the number of carbon atoms of the respective alkane standards, multiplied by 100 .

The quantification of volatile compounds was related to the percentage area of the peak of each compound and to the total area of all peaks normalized in the chromatogram.

\section{Results and Discussion}

\subsection{Volatile compounds in the fresh pulp and dehydrated powder of acerola.}

Aroma is one of the most important attributes in food and it is used to mainly relate the sensory quality of fruit and fruit products. In the determination of volatile compounds of acerola pulp, 25 compounds were found from the sample containing $4 \mathrm{~g}: 10 \mathrm{~mL}$ (Pulp:Water) and the main compounds identified were: ethanol (10.96\%), ethyl acetate $(9.61 \%)$, pent-4en-1- yl propyl carbonate $(8.20 \%)$, ethyl hexanoate $(6.88 \%)$, ethyl butanoate $(6.36 \%)$, 4 pentenyl butanoate $(3.57 \%)$, (E)-2-hexenal $(2.82 \%)$ and 4-pentenol $(2.32 \%)$. For the dilution $(4 \mathrm{~g}: 20 \mathrm{~mL})$ of the pulp, the number of identified compounds decreased, being only the compounds found in the first dilution consisting of ethyl acetate (5.73\%), ethanol $(11.32 \%)$, ethyl butanoate $(5.52 \%)$. However, in the third dilution $(4 \mathrm{~g}: 30 \mathrm{~mL})$ only ethyl acetate $(11.23 \%)$ and ethyl butanoate $(2.34 \%)$ were identified. The P\&T technique generally provides a higher extraction yield, which may be associated with a larger surface of the adsorbent trap in relation to other techniques such as SPME.[6]

$21^{\text {ST }}$ INTERNATIONAL DRYING SYMPOSIUM

EDITORIAL UNIVERSITAT POLITÈCNICA DE VALÈNCIA 
In the dried acerola powder, 20 compounds were found in the samples dried at the two temperatures of 128 and $152^{\circ} \mathrm{C}$ while using a maltodextrin concentration of $26 \%$. This concentration of maltodextrin showed a retention of $80 \%$ of aroma in the dried powder. The powder obtained using $14 \%$ concentration of maltodextrin did not show a better retention of volatile compounds and only 12 compounds were retained. The main compounds identified in the dried powder were ethyl hexanoate $(2.01 \%)$, (E)-2-hexenal (1.95\%), methyl hexanoate $(1.2 \%)$ and methyl acetate $(0.8 \%)$. These volatile compounds were reported previously in other studies on acerola aroma. ${ }^{[7,8,9,10,11]}$ Ethyl hexanoate was the main contributor to acerola aroma and its odor quality resembled that of apple peel, being fruity and sweet. ${ }^{[12,13,14]}$

The concentration of ethyl hexanoate decreased from $6.88 \%$ in the fresh pulp to $2.01 \%$ in the dried powder as showed in the Figure 1 . Nunes et al. ${ }^{[15]}$,studying the effect of drying temperatures in the volatile compounds of guava, reported in spray drying the volatile compounds could be affected by solubility in pulp of fruit lipids and/or residual water, which is probably the major factor contributing to volatiles retention. ${ }^{[16]}$ Therefore, compounds with high vapour pressure and/or low liposolubility tend to be loose the components during drying, whereas compounds with low vapour pressure and/or high liposolubility tend to concentrate in dried powders.

\section{INFLUENCE OF TEMPERATURE}

\section{$8,00 \%$}

$7,00 \%$

$6,00 \%$

$5,00 \%$

$4,00 \%$

$3,00 \%$

$2,00 \%$

$1,00 \%$

$0,00 \%$

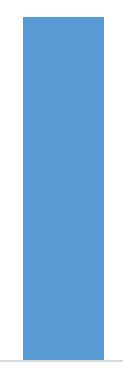

Fresh Pulp

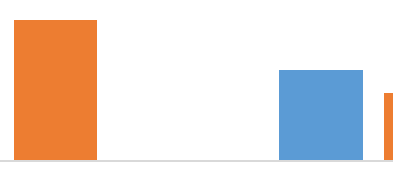

Dehydrated powder at 128 ${ }^{\circ} \mathrm{C}$

Ethyl Hexanoate $\quad$ (E)-2-hexenal

Figure 1: Influence of temperature on the key aroma compounds from acerola pulp

$21^{\text {ST }}$ INTERNATIONAL DRYING SYMPOSIUM EdITORIAL UniVERSITAT POLITÈCNICA DE VALÈNCIA 
Tong Chin et al. ${ }^{[17]}$ studied the influence of temperature on the retention capacity of the volatile compounds of the dried Durian pulp by atomization process and monitored the key aroma compounds, propanethiol and ethyl propanoate, at two temperatures $\left(170^{\circ} \mathrm{C}\right.$ and $130^{\circ} \mathrm{C}$ ), noting that at a temperature of $170^{\circ} \mathrm{C}$ a reduction in the number of volatile compounds occurs.

Other compound that showed reduction was $(E)$-2-hexenal that are reported that together with hexanal it is strongly related to the flavour of fresh guava fruit, providing an herbaceous and fresh aroma note. ${ }^{[18]}$

The retention f volatile compounds can be influenced by maltodextrin. Maltodextrins with higher DE are more hydrolyzed, and these provide more hydroxyl groups for the interactions with volatile compounds. ${ }^{[19]}$ This interpretation is in accordance with one proposed by Reineccius ${ }^{[20]}$, who found that more volatile compounds were retained in the system containing maltodextrins of higher DE values.

\section{Conclusions}

The various combinations used for spray drying od acerola pulp by varying drying air temperature and maltodextrin concentrations had influence on volatile compounds. The concentration of $26 \%$ of maltodextrin preserved more volatile compounds than the concentration of $14 \%$ maltodextrin. Compounds classified as key aroma compounds such as ethyl hexanoate and $(E)$-2-hexenal in fresh acerola pulp were retained in the acerola dried powder. These results prove that use of maltodextrin in spray drying of acerola pulp helps in retention of key aroma compounds in dried acerola powder.

\section{References}

[1] Silva, M.L.S.; Menezes, C.C.; Portela, J.V.F.; Alencar, P.E.B.S.; Carneiro, T.B. Teor de carotenoides em polpas de acerola congeladas. Revista Verde de Agroecologia e Desenvolvimento Sustentável, 2013, 8 (1), 170-173.

[2] Maia, G. A., Sousa, P. H. M.; Santos, G. M.; Silva, D. S.; Fernandes, A. G.; Prado, G. M. Efeito do processamento sobre os componentes do suco de acerola. Ciência e Tecnologia Alimentar, Campinas, 2007.

[3] Maciel, M.I.S., Melo, E.A.; De Lima, V.L.A.G.; Da Silva, W.S.; Maranhão, C.M.C.; De Souza, K.A. Características sensoriais e físico-químicas de geléias mistas de manga e acerola. Boletim do Centro de Pesquisa de Processamento de alimentos, 2011, 27 (2), 13. 
[4] Silva, R.N.G.; Figueiredo, R.M.F.; Queiroz, A.J.M.; Galdino, P.O. Armazenamento de umbu-cajá em pó. Cienc. Rural [online]. 2005, 35 (5), 1179-1184.

[5] Mata, M.E.R.M.C; Medeiros, S.S.A.; Duarte, M.E.M. Microencapsulamento do umbu em pó com diferentes formulações de maltodextrina: estudo do tamanho das partículas por microscopia eletrônica. Revista Brasileira de Produtos Agroindustriais, 2005, 7 (1), 59-70.

[6] Povolo, M.; Contarini, G. Comparison of solid-phase microextraxtion and purge and trap methods for the analysis of the volatile fraction butter. Journal of Chromatography A, 2003, 985, 117-125.

[7] Boulanger, R.; Crouzet, J. Identification of the aroma components of acerola (Malphigia glabra L.): free and bound flavour compounds. Food Chemistry, 2001, 74(2), 209-216.

[8] Carasek, E., \& Pawliszyn, J. Screening of tropical fruit volatile compounds using solid-phase microextraction (SPME) fibers and internally cooled SPME fiber. Journal of Agricultural and Food Chemistry, 2006, 54 (23), 8688-8696.

[9] Pino, J. A.; Marbot, R. Volatile flavor constituents of acerola (Malpighia emarginata DC.) fruit. Journal of Agricultural and Food Chemistry, 2001, 49 (12), 5880-5882.

[10] Schippa, C.S.; George, G.; Fellous, R. Constituans volatils de l'acerola. Parfums Cosmet. Aromes, 1993, 113, 81-84.

[11] Vendramini, A. L.; Trugo, L. C. Chemical composition of acerola fruit (Malpighia punicifolia L.) at three stages of maturity. Food Chemistry, 2000, 71 (2), 195-198.

[12] Acree, T. E., \& Arn, H. (2004). Flavornet and human odor space. Available from: http://www.flavornet.org/flavornet.html. Accessed 20 October 2017.

[13] Garruti, D. S.; Franco, M.R.B.; da Silva, M.A.A.P., Janzantti, N.S.; Alves, G.L. Assessment of aroma impact compounds in a cashew apple-based alcoholic beverage by GC-MS and GC-olfactometry. LWT - Food Science and Technology, 2006, 39 (4), 373-378.

[14] MacLeod, A.J.; Pieris, N.M. Volatile flavor components of soursop (Annona muricata). Journal of Agricultural and Food Chemistry, 1981, 29 (3), 488-490.

[15] Nunes, J.C.; Lago, M.G.; Castelo-Branco, V.N.; Oliveira, F.R.; Torres, A.G.; Perrone, D.; Monteiro, M. Effect of drying method on volatile compounds, phenolic profile and antioxidant capacity of guava powders. Food Chemistry, 2016, 197, 881-890.

[16] Taylor, A. J. Physical chemistry of flavor. International Journal of Food Science \& Technology, 1998, 33, 53-62. 
[17] Tong Chin, S.; Nazimah, S.A.H.; Quek, S.Y.; Man, Y.B.C.; Rahman, R.A.; Hashim, D.M. Changes of volatiles' attribute in durian pulp during freeze- and spray-drying process, 2008, 41, 1899-1905.

[18] Pino, J. A.; Bent, L. Odour-active compounds in guava (Psidium guajava L. cv. Red Suprema). Journal of the Science of Food and Agriculture, 2013, 93, 3114-3120.

[19] Mao, L.; Ross, Y.H.; Miao, S. Effect of maltodextrins on the stability and release of volatile compounds of oil-in-water emulsions subjected to freezeethaw treatment. Food Hydrocolloids, 2015, 50, 219-227.

[20] Reineccius, G. A. Controlled release techniques in the food industry. In S. J. Rich, \& G. A. Reineccius (Eds.), Encapsulation and controlled release of food ingredients. Washington: American Chemical Society. 1995, 8-25. 